HID 41 (2014)

\title{
LAADMINISTRACIÓN DE LA CASA DE VELASCO EN EL SIGLO XVII ${ }^{1}$
}

\author{
THE ADMINISTRATION OF THE VELASCO’S HOUSE \\ IN THE $17^{\text {TH }}$ CENTURY
}

\author{
José Antonio Cuesta Nieto \\ cuestanietoja@yahoo.es
}

Resumen: Los Velasco, condestables de Castilla y duques de Frías, acumularon un enorme conjunto de estados señoriales, lo que les convirtió en una de las casas nobiliarias más importantes de toda la Corona de Castilla. Su estructura administrativa tomó como modelo la de la Casa Real. Durante el siglo XVII los duques de Frías se propusieron mejorar la gestión administrativa para sanear su estado financiero regulando tanto el funcionamiento de los órganos centrales como de las mayordomías de cada uno de sus estados.

PALABRAS CLAVE: Castilla, duques de Frías, administración señorial, mayordomías, siglo XVII.

Abstract: The Velasco, the High Constable of Castilla and Dukes of Frías, accumulated a huge number of noble states that made them one of the most important aristocratic families of the Crown of Castile. Its administrative structure was taken as a model by the Royal House. During the $17^{\text {th }}$ century the Dukes of Frías proposed to improve the administrative structure in order to consolidate their financial statement through the regulation of the central management as well as the stewardship of its states.

KEYwORDS: Castile, dukes of Frías, noble administration, stewardship, $17^{\text {th }}$ century.

1. Abreviaturas utilizadas. $\mathrm{AHPBu}=$ Archivo Histórico Provincial de Burgos; $\mathrm{SN}, \mathrm{AHN}=\mathrm{Sec}-$ ción Nobleza, Archivo Histórico Nacional. 


\section{INTRODUCCIÓN}

La Casa de Velasco, hegemónica en buena parte de Castilla la Vieja, fue la de los Condestables de Castilla y de León y duques de Frías y cabeza de la nobleza del reino ${ }^{2}$. El objetivo de este estudio es analizar su estructura administrativa y las reformas que de la misma plantearon los Condestables en el siglo XVII; para ello analizaremos los problemas de gestión de personal (mayordomos de los partidos) y su relación con la situación financiera de la casa.

Nuestras fuentes son unas instrucciones de gobierno, unas ordenanzas de mayordomos y varios expedientes sobre la gestión de varios mayordomos que analizados conjuntamente adquieren coherencia y nos permiten descender de los planteamientos generales a los problemas reales. Partíamos de la hipótesis de que todo esfuerzo regulador responde a la necesidad de atajar problemas.

Las grandes casas señoriales mantuvieron una administración central que regía y coordinaba a los oficiales de cada uno de sus Estados y que estaba diseñada a imitación de la administración de la Casa Real ${ }^{3}$. En las de los duques de Arcos, los duques de Osuna, los marqueses de Villena, los duques de Alba, los duques del Infantado y los duques de Feria la organización era similar a la de los duques de Frías ${ }^{4}$.

Varias casas (Arcos, Feria, Osuna, Villena) contaban con una administración central compuesta por tres oficinas básicas dotadas con el correspondiente personal subalterno ${ }^{5}$. Eran la Secretaría que dirigía la política de la casa y asistía

2. E. González Crespo. Elevación de un linaje nobiliario castellano en la Baja Edad Media: los Velasco. Tesis doctoral. Madrid, 1981. A. Franco Silva. Entre los reinados de Enrique IV y Carlos V. Los Condestables del linaje Velasco (1461-1559). Jaén, 2006.

3. D. García Hernán. Aristocracia y señorío en la España de Felipe II. La Casa de Arcos. Granada, 1999, p. 23. A. Carrasco Martínez. El poder de la sangre. Los duques del Infantado. Madrid, 2010, pp. 389-390.

4. I. Atienza Hernández. Aristocracia, poder y riqueza en la España moderna. La Casa de Osuna, siglos XV-XIX. Madrid, 1987, pp. 318-327. A. Carrasco Martínez. El régimen señorial en la Castilla Moderna: Las tierras de la Casa del Infantado en los siglos XVII y XVIII. Tesis doctoral. Madrid, 1991, pp. 90-166, y El poder de la sangre..., pp. 250 y ss. J. Ortuño Molina. Realengo y señorío en el Marquesado de Villena. Organización económica y social en tierras castellanas a finales de la Edad Media (1475-1530). Murcia, 2005, pp. 115-122 y 127-136; D. García Hernán. Aristocracia y señorio en la España de Felipe II. La Casa de Arcos. Granada, 1999, pp. 41-54; J.M. Calderón Ortega. El Ducado de Alba. La evolución histórica, el gobierno y la hacienda de un estado señorial (siglos XIV-XVI). Madrid, 2005, pp. 187-215 y 305-311, y "El gobierno de la Casa de Alba (siglos XIV-XVI)", en G. del Ser Quijano (coord.). Congreso V centenario del nacimiento del III duque de Alba Fernando Álvarez de Toledo. Ávila, 2008, pp. 119-153. L. Salas Almela. Medina Sidonia. El poder de la aristocracia, 1580-1670. Madrid, 2008, pp. 84-94. J.M. Valencia Rodríguez. El poder señorial en la Edad Moderna: La casa de Feria (siglos XVI-XVII). Cáceres, 2010, Tomo I, pp. 445 y ss.

5. En el marquesado de Villena la administración central constaba de la Secretaría, con un secretario y otros oficiales subalternos, varios contadores y un tesorero. En cada villa había un mayordomo que administraba la hacienda señorial y que en ocasiones era la misma persona que desempeñaba la alcaidía. En materia judicial, el órgano central era el Consejo, compuesto por letrados y, al parecer, creado después de 1480; recibía en apelación las sentencias de los corregidores señoriales, alcaldes mayores o gobernadores de las villas del Estado. El ducado de Osuna se dividió en 1605 en dos distritos -Castilla y Andalucía- que contaban con una Junta con un contador general al frente y en cada una 
directamente a su titular, la Contaduría de la que dependía el control de los mayordomos de las villas y partidos y la Tesorería que recibía el dinero enviado por los mayordomos y hacía los pagos correspondientes. La administración señorial se completaba con la Audiencia señorial, que era el tribunal de apelación de las sentencias dadas por los corregidores y alcaldes mayores de las villas de señorío ${ }^{6}$.

En otras casas (Alba, Infantado y Medina Sidonia) y en el arzobispado de Toledo ${ }^{7}$ se dio un paso más y por encima de los anteriores organismos se creó un Consejo señorial a imitación del Consejo Real, reordenado por los RR. CC. en $1480^{8}$. Asumía las funciones judiciales de la Audiencia señorial a las que añadía la dirección de lo político y económico. Estaba integrado por el secretario, un alcalde mayor, uno o más contadores, algunos letrados y, según los casos, otros oficiales señoriales ${ }^{9}$. En el siglo XVIII decaen por su excesivo coste y escasa utilidad ${ }^{10}$. Secretaría, Contaduría y Tesorería seguían desempeñando todas las tareas ordinarias.

de las villas un administrador de rentas. En el ducado de Arcos la administración central descansaba en una Contaduría general, que residía en Marchena, con un contador mayor, los contadores y un tesorero, ante la que daban cuentas anualmente los mayordomos de los señoríos y los arrendadores de rentas; la Audiencia señorial, con sede en Marchena, recibía las sentencia en apelación de corregidores y alcaldes. En el ducado de Feria la Contaduría General residía en Zafra, capital del estado, y contaba con un contador mayor, un tesorero, un oficial y, en el siglo XVII, un alguacil mayor de la hacienda; del contador mayor dependían los mayordomos del pan, que a veces eran los alcaides de las fortalezas, y el mayordomo de la dehesa de Perales.

6. El funcionamiento de la Audiencia de Osuna y del Tribunal y Juzgado de Apelaciones de Baena y Cabra quedó regulado mediante sendas ordenanzas de 1582 y 1634 respectivamente. D. García Hernán. El gobierno señorial en Castilla. La presión y concesión nobiliaria en sus documentos (siglos XVI-XVIII). Madrid, 2010, p. 77.

7. A.M. Guilarte. El régimen señorial en el siglo XVI. Valladolid, 1988, p. 198.

8. La primera noticia del Consejo de los duques de Alba data de 1484. J.M. Calderón Ortega. "El gobierno y la administración de un Estado Señorial: El Consejo de los Duques de Alba (1484-1531)", En la España Medieval, n 19, 1996, pp. 312 y 314.

9. En el Ducado del Infantado el órgano supremo es el Consejo, evolución del anterior tribunal de apelación, integrado por letrados y con funciones judiciales -tribunal de apelación-, de gobierno y económicas; a principios del siglo XVII al trasladarse la residencia señorial de Guadalajara a Madrid y para reducir gastos fue sustituido por una Junta integrada por el secretario personal del duque, dos o tres contadores, un juez de apelaciones y los abogados convirtiéndose en una simple reunión periódica de los principales funcionarios de la Casa; en el siglo XVIII se potencia la Secretaría General como órgano de gobierno. La gestión de la hacienda señorial estaba en manos de la Contaduría, subordinada al Consejo hasta 1620, y la Tesorería, subordinada a la Contaduría. En el Ducado de Alba el Consejo, documentado por primera vez en 1484, tenía funciones de gobierno, hacendísticas y judiciales -tribunal de apelación- y lo integraban el contador, el secretario, el alcalde mayor, el mayordomo, el alcaide de Alba y un letrado; a partir de 1509 lo preside un gobernador, desaparecen el alcalde mayor y el alcaide de Alba y se intensifica la presencia de letrados; aunque desde 1438 la Casa de Alba nombraba un alcalde mayor para gran parte del Estado, cuando se creó el Consejo señorial se integró en él. Desde principios del siglo XVI aparecen dos secretarios, uno del duque y otro del Consejo. Aunque había un tesorero-pagador no formaba parte del Consejo. En el Ducado de Medina Sidonia también encontramos un Consejo con funciones gubernativas y judiciales; en 1640 se componía de tres oidores, tres jueces, un presidente y un escribano. La Contaduría, con un contador mayor, en 1539 se amplió con tres contadores y tres oficiales de los libros; de ella dependía un tesorero.

10. D. García Hernán. El gobierno señorial en Castilla. La presión y concesión nobiliaria en sus documentos (siglos XVI-XVIII). Madrid, 2010, p. 106. 
Hacia 1530, la administración central de los Velasco estaba compuesta por cinco secretarios, un contador y un tesorero; las apelaciones de las sentencias de las justicias de las villas quedaban para los alcaldes mayores de Briviesca, que eran cuatro ${ }^{11}$. En el siglo XVII nos encontramos con los mismos tres organismos de otras casas de la aristocracia, Secretaría, Contaduría y Tesorero, dependencias que se completaban con los archivos, pero no un Consejo.

\section{LA ADMINISTRACIÓN CENTRAL DE LA CASA Y LAS INSTRUCCIONES DE 1641}

En el siglo XVII la situación financiera de la Casa de Velasco, como la de todas las de la aristocracia, sufrió una crisis que trató de ser afrontada por los Condestables. En 1641 D. Bernardino Fernández de Velasco y Tovar, VII Condestable de Castilla y VI duque de Frías, dejaba al frente de su casa a su hermano Luis de Velasco, marqués del Fresno, con unas instrucciones ${ }^{12}$ cuya finalidad no era sólo garantizar el mantenimiento de la administración durante su ausencia, sino proceder a su reforma. Proyectos de reforma similares mediante unas ordenanzas para reorganizar la contaduría ${ }^{13}$ se propusieron en 1615 en el ducado de Baena ${ }^{14}$, en 1620 y 1657 en el ducado del Infantado ${ }^{15}$, en 1638 en el marquesado de Villena ${ }^{16}$ y hacia 1651 en el ducado de Medina Sidonia ${ }^{17}$.

\subsection{La Secretaría}

El duque, o su lugarteniente, dirigía la Casa desde la Secretaría desde donde se remitían las provisiones señoriales y las numerosas cartas con que se transmitían órdenes a los oficiales semanalmente. A través de ella se proveían los títulos de alcaides, corregidores y alcaldes mayores, alguaciles mayores, jueces de residencia, escribanos y procuradores de las audiencias de villas y jurisdicciones; también

11. SN, AHN, Frías, leg. $93 / 4$ y 3 .

12. 1641, junio, 2. Madrid. "Instrucçiones que el señor Marqués de Fresno, mi hermano, a de obseruar y hacer guardar a los ministros y criados de mi Casa y Estados durante lo que estubiere ausente con declaración de que a los dichos ministros y criados no se les deja más ynstructión que las que ban en este quaderno". SN, AHN, Frías, leg. 402/16. Comentadas por M.F. Gómez Vozmediano. "La gestión patrimonial de la aristocracia castellana...”, p. 255.

13. M.F. Gómez Vozmediano. "La gestión patrimonial de la aristocracia castellana...”, p. 251.

14. D. García Hernán. El gobierno señorial en Castilla. La presión y concesión nobiliaria en sus documentos (siglos XVI-XVIII). Madrid, 2010, pp. 83-87. En la segunda mitad del siglo XVIII aprobaron ordenanzas similares el marqués de Villafranca y de los Vélez (1757) y el XVI marqués de Astorga (1783). Íbidem, pp. 87-95, y M.F. Gómez Vozmediano. "La gestión patrimonial de la aristocracia castellana...", pp. 256-257.

15. En 1591 se aprobaron unas ordenanzas para la Contaduría, que estaba subordinada al Consejo ducal; en 1620 se aprobaron otras que ampliaban las funciones de la Contaduría y la liberaban de la tutela del Consejo en los asuntos ordinarios, a las que en 1657 se añadieron once artículos más. A. Carrasco Martínez. El poder de la sangre..., pp. 393-395.

16. M.F. Gómez Vozmediano. "La gestión patrimonial de la aristocracia castellana...”, p. 254.

17. L. Salas Almela. Medina Sidonia..., p. 420. 
se libraban las confirmaciones de los oficios concejiles ${ }^{18}$. En 1642 el marqués del Fresno realizó nueva tasación de los derechos a llevar por el despacho de los títulos para los distintos oficios que nombraba la Casa, al parecer, con una finalidad puramente hacendística ${ }^{19}$.

La correspondencia recibida debía abrirla personalmente el Condestable y la emitida debía mantenerla bajo llave hasta ser despachada; debía tener la llave el secretario. El mejor día de la semana para enviar la correspondencia era el miércoles porque es este el día en que ban todas las cartas seguras.

Todas las cartas recibidas se guardarían ordenadas por su fecha formando un legajo cada año. Y todas las provisiones despachadas debían copiarse en un libroregistro -no debían firmarse hasta estar copiadas-porque en esta parte a abido gran descuido que me a obligado a mandar sacar de los tribunales eclesiásticos tantos de los títulos que e dado a capellanes, benefiçiados y curas. Del resto de despachos, como instrucciones, comisiones y otras cosas generales, debía hacerse otro libro-registro.

También se enviaban a la Secretaría los autos de las residencias. El Condestable ordenaba que se guardasen en el Archivo en su puesto dos autos de cada lugar para que pudieran servir de prueba en los pleitos. Los demás autos de residencia convenientemente encuadernados debían remitirse a Briviesca, a la Audiencia de los alcaldes mayores de la Casa y Estado.

La actuación de los agentes y abogados de la Casa ante los tribunales también se dirigía desde la Secretaría. El Condestable llevaba memoria de los papeles que les remitía a fin de podérselos reclamar después.

En los despachos habituales de la Secretaría el Condestable consideraba fundamental mantener la neutralidad y la agilidad diferenciando los asuntos de justicia, que debían consultarse con los abogados, de los de gobierno. Así, rechazaba admitir intercesiones en los asuntos judiciales y guiarse sólo por el parecer de los abogados, es decir, por el respeto al derecho; los nombramientos de oficios que vacaren debían hacerse en personas beneméritas a las que el propio señor debía examinar con todo secreto; las peticiones y recursos que llegaren de los lugares del Estado debían responderse con la mayor brevedad con lo que se excusa el hazer costas a los lugares y personas que los ynbían. En todo caso, el señor debía consultar la resolución de todos los asuntos importantes con el secretario y las demás personas que considerare necesario.

Los corregidores y alcaldes mayores tendían a actuar con independencia. El Condestable denunciaba que solían omitir la ejecución de las órdenes que les enviaba el secretario y la toma de las informaciones que se les pedía, en especial las referidas a la hacienda señorial siendo la cosa prinçipal de su obligazión; en este caso disponía que se les privase del oficio.

18. La especificación de las funciones de las Secretarías del duque de Baena a principios del siglo XVIII y del marqués de Astorga en 1783 en D. García Hernán. El gobierno señorial en Castilla. La presión y concesión nobiliaria en sus documentos (siglos XVI-XVIII). Madrid, 2010, pp. 107-110.

19. 1642, diciembre, 6. Madrid. SN, AHN, Frías, leg. 632/52. 
El control de estos oficiales se realizaba especialmente a través de los juicios de residencia. De ahí que debiera cuidarse a qué personas se comisionaba para tomarlos y, aun con todo, exigirles fianza ordinaria de que remitirían los autos a la Secretaría en un plazo predeterminado. Estas fianzas se guardarían todas juntas en un estante.

Además, siempre que fuese posible se debía hacer grazia a los vasallos mientras no repercutiere en la Hacienda señorial, pues entonces el Condestable debía considerar el caso detenidamente.

\subsection{La Contaduría}

La Contaduría ${ }^{20}$ llevaba la gestión económica de la casa ${ }^{21}$ y supervisaba y coordinaba la actuación de los mayordomos de los partidos ${ }^{22}$. A su cargo estaban las decisiones económicas y la provisión de oficios para los estados ${ }^{23}$. El tesorero recibía el dinero líquido y cobraba las libranzas que enviaban los mayordomos de los partidos y pagaba las que despachaban los contadores ${ }^{24}$.

Desde 1628 al finalizar cada año la Contaduría hacía una previsión de las rentas totales de la Casa del año siguiente distribuyendo ese importe por mayordomías -repartimiento- ${ }^{25}$ y se hacía a cada mayordomo otorgar carta de obligación de que lo pagaría en tres tercios ( 1 de mayo, 1 de octubre y 1 de febrero del año siguiente) girándolo a la casa del tesorero ${ }^{26}$. Concluido el año, los mayordomos

20. En 1783 la del marquesado de Astorga tenía un contador, un oficial mayor, cinco oficiales y tres subalternos y en 1791 se estableció que la de la Casa de Osuna constase de un contador mayor, un oficial mayor, un oficial primero, un oficial segundo, un oficial tercero, dos escribientes y un portero. M.F. Gómez Vozmediano. "La gestión patrimonial de la aristocracia castellana...”, p. 250 y 257.

21. Podían ejercer un papel mucho más relevante de lo establecido. Gómez Ruiz de Mercado, contador del II conde de Monteagudo durante 30 años hasta 1547, adelantó importantes cantidades de dinero a su señor para pagar a sus acreedores y cubrir otras deudas. M. Diago Hernando. "El endeudamiento de la alta nobleza castellana durante la primera mitad del siglo XVI: El caso del segundo conde de Monteagudo (1506-1547)", Chronica Nova, 39 (2013), pp. 194-195.

22. Aunque J. Ortuño no ve claro si los contadores del Marquesado de Villena estaban encuadrados por estados o formaban parte de una administración común a todos los estados. J. Ortuño Molina. Realengo y señorio..., pp. 117-118. Una definición general en M.F. Gómez Vozmediano. "La gestión patrimonial de la aristocracia castellana...”, pp. 240-241.

23. En el Ducado de Alba, los contadores, documentados a partir de 1441, aparecían con funciones judiciales en el ámbito de su competencia. J.M. Calderón Ortega. El Ducado de Alba..., pp. 307-309.

24. En el Ducado de Arcos "su misión principal era la custodia del dinero que llegaba a la contaduría y la realización de muchos pagos ordenados por el señor". En esta casa tenían las llaves de las arcas el gobernador, el contador mayor y el tesorero. D. García Hernán. Aristocracia y señorío..., pp. 41-43.

25. El contador del ducado de Gandía hacía un cálculo aproximado del presupuesto de la casa para el año siguiente -tanteo-y de dónde lo obtendría. J. Casey. El Reino de Valencia en el siglo XVII. Madrid, 1983, p. 144.

26. El 30 de enero de 1712 el mayordomo de Salas de los Infantes, D. Juan Antonio Fernández de la Peña, otorgaba carta de obligación por la que se obligaba a pagar 1.321.866 mrs. de las rentas de su mayordomía de ese año de 1712 en tres tercios de $40.725 \mathrm{mrs}$. poniendo el dinero en Madrid en casa del tesorero. AHPBu, Protocolos Notariales, leg. 3.113/2, s.f. El procedimiento era similar en la Casa del Infantado. A. Carrasco Martínez. El poder de la sangre..., p. 397. 
acudían a la contaduría a dar cuenta detallada; se hacía de forma similar en el ducado de $\operatorname{Arcos}^{27}$.

Los asuntos de cada día los señalaba el propio Condestable; se trabajaba dos horas por la mañana y una por la tarde, salvo los días de despacho en que se trabaja tres horas por la mañana y dos por la tarde ${ }^{28}$.

En 1641 se dividió la Contaduría en dos secciones, la de la Casa y la de los Estados. La segunda sección se dividió en otras dos subsecciones, la de lo secular y la de lo eclesiástico, pues teniendo como tengo tantos patronazgos y obras pías no está segura mi conzienzia mientras de esto no aya luz y claridad.

Para el trabajo habitual debían instalarse unas estanterías y unos cajones así del tamaño de libros agujerados como de quartilla de papel holgada; cada cajón y cada libro llevaría título identificativo. Se confeccionaría un librito que sirviera de índice de los cajones y papeles de cada uno para manejo de los oficiales. Los papeles que se consideraran innecesarios deberían romperse.

El Condestable se quejaba del poco orden que se había llevado hasta entonces en la Contaduría y decía:

Hermano mío. Este trauajo es tan esenzial como puede aber mostrado a V. S. la experienzia, pues apenas e hallado papel en la Contaduría quando le e abido menester y en medio de mis ahogos y trauajos que e pasado a querido Dios que me falte esto como lo demás y assí suplico a V. S. que sin congojarse y templando el ferbor de su condiçión y buen zelo de lo que me toca disponga V. S. que esto se haga con efeto, pues de ello depende mucho más de lo que puedo esperar en toda la vida...

Más tarde comentaba:

Bien quisiera escusar en la Contaduría tener puesto general de papeles porque es el camino mejor para que ofiçial de poco talento o poltrón confunda todo lo demás por aorrar de discurso y tranajo, pero si no pudiere escusarse esto, que lo dejo a la prudenzia de V. E. y de mis ministros, mandará V E. formarle en lo que no pudiere escusarse y con las calidades y distinciones que en todo lo demás que quedare referido.

Para los distintos asuntos se formarían siete libros:

- Libro de deudas a favor y en contra, indicando si se pagaban a los plazos vencidos o si estaban consignadas en alguna renta y su calidad, es decir, si eran de cobro seguro, dudoso o fallido.

- Libro de los juros que cobraba recogiendo si había atrasos pendientes y quién los pagaba porque en esto a abido descuido grande y no se a cuidado

27. Los mayordomos del Ducado de Arcos funcionaban del mismo modo que los del Ducado de Frías. D. García Hernán. Aristocracia y señorío..., pp. 43-45.

28. Un horario similar, precisando hora de entrada y salida y diferenciando horario de verano del de invierno, se estableció en las contadurías de otras casas. M.F. Gómez Vozmediano. "La gestión patrimonial de la aristocracia castellana...", p. 272. 
de esta materia ni a tenido mano fixa por donde corra y Francisco Xil de la Cotera no a hecho sino enredarla.

- Libro de acostamientos y gaxes que se pagaban tanto en concepto de salarios como "por merced" u otra razón.

- Libro de las limosnas perpetuas y temporales que se pagaban indicando su condición y los atrasos que se pudieran deber.

- Libro de los testamentos de su abuelo, sus padres, su mujer Dña. María Girón y de su hermano el conde de Haro. Se debería analizar si de los dos últimos testamentos quedaba alguna disposición por cumplir y sobre ello consultar a teólogos y abogados. El Condestable necesitaba dejar resuelto cualquier asunto a este respecto para hacer su testamento que es la cosa que más deseo.

- Libro de los repartimientos hechos por los mayordomos desde 1628, en que se hizo el primero. Se confeccionarían en papel sellado y por duplicado guardando el original en la contaduría y remitiendo la copia a los mayordomos cuando hubiese duda.

- Dos libros con todos los cargos, uno con los de la Casa y otro con los del Estado.

Asimismo, debían formarse los doce libros de la memoria que entregó en 1628 el contador Diego de Arredondo Agüero que, al parecer, sirvió la contaduría hasta ese año.

El resto de papeles se ordenarían en cajones de la siguiente manera:

- Correspondencia de los administradores, arrendadores y mayordomos agrupada en un legajo por cada partido.

- Memoriales resueltos de que hubieren salido despachos de la Contaduría agrupados en un legajo los de la Casa y en otro los de los Estados.

- Escrituras de fianza y obligación de los mayordomos, administradores y arrendadores puestos por orden de antigüedad separando los que estaban en vigor.

- Libros de cuentas de los mayordomos, administradores y arrendadores ordenados por antigüedad diferenciando los de carácter seglar de los de carácter eclesiástico.

- Cartas de pago de cualquier tipo. Las de mayor importe de las que no quedase otro testimonio se trasladarían al archivo dejando una nota en el lugar que las correspondiere.

- Cuentas de los tesoreros por orden de antigüedad en que se a de poner mucho cuidado por depender de ello la suma de todo lo que es la haçienda.

- Cuentas de oficiales en que figuren lo que han recibido, lo que se les debe y lo que se les libra sobre algún efecto.

- Censos contra la Casa divididos por partidos reclamando a los mayordomos copia de las escrituras si no las hubiere en la Contaduría. El Condestable estaba preocupado por este asunto, pues, según dice, había pagado muchos años un censo en San Asensio que no debía. Por la misma razón, pide que los mayordomos envíen las cartas de pago todos los años. 
- Alcance líquido de las cuentas que dieren los mayordomos, arrendadores y administradores para hacer un resumen por quinquenios en el que quedase reflejada la evolución de las rentas de cada partido y, si han descendido, se pueda anotar la causa, pues avnque esto siempre está de manifiesto en las qüentas es muy esençial esto para que se hagan sin embarazo los repartimientos de los mayordomos y ajuste de gastos a la pusibilidad de mi hazienda.

- Testimonios de venta del pan ordenados en un legajillo por partidos para utilizarlos al dar cuentas los mayordomos.

- Este trabajo se completaría con una serie de libros-registro:

- Libro con las libranzas que se mandaba pagar al tesorero.

- Libro con las cuentas de los gajes y sueldo que el rey pagaba al Condestable detallando los oficios donde se an de sacar zertificaçiones para que se haga el pago. Así, cada año se podría saber lo que le debía la Real Hacienda y hacer cuentas con el mayordomo del rey.

- Libro-registro de las órdenes generales que se despacharen a los mayordomos, o las de despacho del pan y otras. Se excluyen las órdenes ordinarias de administrazión de hazienda.

- Libro-registro de las libranzas que se despacharen sobre los mayordomos, arrendadores y administradores para llevar cuenta de lo cobrado de cada uno.

- Libro-registro de las órdenes que se despacharen a los agentes de la Casa en los tribunales para los pleitos en materia hacendística.

- Libro con la relación de las ejecutorias de los pleitos en materia de hacienda que se guardaren en la Contaduría.

De toda esta labor se ocuparía D. Juan Guerrero y un oficial que se contrataría para el efecto y al que se pagaría por días.

Se debía mantener correspondencia regular con los mayordomos dándoles instrucciones sobre lo que les hubiere correspondido en el repartimiento en que todos tienen grande omisión, pues si algún mayordomo se retrasaba en pagar había que sacar requisitoria y mandar ejecutor contra él; debía avisárseles con dos meses de antelación, pues así no podrían alegar ignorancia.

El control de los mayordomos era su función principal. El Condestable insiste en que cuando vinieren a dar cuentas deberían traerlas formadas para abreviar; asimismo, se liquidarían los alcances evitando incluirlos en las cuentas de los años siguientes, ya que así los mayordomos se apoderaban de las rentas de la Casa. Dada la cuenta, los mayordomos debían firmar el repartimiento de inmediato sin permitirles marchar de la Casa, porque en yéndose vna vez al estado se dilata mucho la acçetaçión y se haze no como combiene, sino como ellos quieren.

Uno de los asuntos que deterioraba el ingreso señorial era la venta del pan. El Condestable insiste en que las decisiones al respecto las tome directamente el contador y no se deje a arbitrio de los mayordomos el que lo vendan o no ni se pase el tiempo en que más combenientemente pueda salir de los frutos. 
En todo caso, el Condestable creía conveniente no apretar demasiado a los mayordomos, pues no era fácil buscar otros mejores para algunos partidos:

\begin{abstract}
A los mayordomos procurará V. S. no se les pida más de lo que fuere raçón para que en la parte de cómo administran y en la de açeptar los repartimientos se tenga particular cuidado de que hagan lo que es justo y raçón sin consentirles escusas ni fieros de dejar las mayordomías porque ay muchos que se balen de estos pretextos para ser señores de mi hazienda y no acudir más de lo que a ellos se les antoja.
\end{abstract}

\title{
2.3. La Tesorería
}

Tenía un tesorero al frente ${ }^{29}$. El dinero efectivo que llegare a la Casa entraría en su poder, si bien se guardaría un recibo en la Tesorería y otro en la Contaduría; se debería llevar el mismo control con las letras de cambio.

En el pago de las libranzas que despachaba la Contaduría, el tesorero debería anteponer siempre los asuntos más urgentes. Tampoco debería pagar los salarios de los criados sin haber recibido la libranza oportuna.

\subsection{El archivo central}

Los archivos presentaban la misma estructura que los órganos administrativos. En el palacio ducal había un archivo central en el que se depositaba la documentación más importante, es decir, los privilegios y demás títulos de propiedad junto con la documentación judicial que podía tener valor en los tribunales ${ }^{30}$; la contaduría tenía un archivo propio de carácter más administrativo, mientras en cada una de las mayordomías existía un archivo de los pueblos de su partido ${ }^{31}$. Cuando se consideraba los mayordomos remitían a la Contaduría copias auténticas ante escribano de los documentos que se necesitaran.

El archivo central se componía de una sala principal y un aposento pequeño con una bentanilla. Se cerraría con tres llaves que custodiarían el marqués del Fresno, D. Francisco de Porres y D. Pedro de Salinas y se prohibía extraer documentos originales sino copias y, si era preciso, traslados judiciales. Para mayor garantía, se trabajaría a puerta cerrada y sin combersaçión. Uno de los mayores

29. En la Casa del Infantado había un tesorero general y otro de cámara que atendía los gastos corrientes de la casa señorial, ambos dependientes de los contadores. A. Carrasco Martínez. El poder de la sangre..., pp. 395-397.

30. La organización del archivo del marqués de Astorga a finales del siglo XVIII en D. García Hernán. El gobierno señorial en Castilla. La presión y concesión nobiliaria en sus documentos (siglos XVI-XVIII). Madrid, 2010, pp. 132-133.

31. Se conservan dos inventarios del archivo de Salas de los Infantes. El primero es de 29-VIII1609: "en casa del doctor Francisco de Morcate, veçino de esta dicha villa, está un arca pequeña donde están papeles tocantes a la Jurisdiçión de Su Excelençia del Condestable de Castilla y de León, mi señor, ansí en lo tocante a esta villa como a otros lugares de la Casa de Salas”. En 22-V-1631 se efectúa otro por orden del gobernador en casa de Dña. Mariana de Morcate, viuda de Juan de Santa Gadea, vecino y mayordomo de rentas. SN, AHN, Frías, leg. 462/57 y 58. 
temores del Condestable era que pereciera en un incendio, por lo que prohibía el trabajo nocturno, necesariamente con velas, y exigía que todos los papeles al acabar el día quedasen en sus cajones.

El Condestable mandaba depositar en el archivo todos los papeles necesarios para la contaduría. Se especifica que se debían archivar:

- Los apeos.

- lo que tocare a pleytos, prebilexios, títulos y otras cosas que no son del manejo de la administrazión de la haçienda; se habían guardado en el Archivo varios pleitos que estaban en manos de los agentes de la Casa ante los tribunales reales.

- Cuentas.

- Correspondencia de mayordomos.

- ynstruçiones y otras cosas de contaduría que deben quedar en ella.

El trabajo se establecía del siguiente modo:

- Todos los papeles que hubiere en el archivo o que entraren para ser inventariados deberían colocarse en un cajón sin que quedase ninguno encima de las mesas durante la noche. Cada día se sacarían sólo los que se inventariasen.

- Había una serie de papeles antiguos de los que el escribano había sacado copia. Estas copias deberían pasarse a papel sellado de a 8 rs. y autentificarse judicialmente poniéndose junto con los originales. De varios documentos se conserva el original y una o más copias.

- Cada día el marqués del Fresno y D. Pedro de Salinas trabajarían juntos en el Archivo al menos dos horas por la mañana y otra por la tarde.

- Finalmente, se haría un inventario nuevo - había uno bastante incompleto que se manda quemar- que quedase en el Archivo y

se le ha de poner vna barilla de hierro que atrabiese con dos candados y la encuadernaçión a de ser de vezerro y las ojas doradas y muy curioso y se ha de azer para él vna bolsa de damasco en que ande porque no se llene de poluo y esté libre de la polilla que puede pegárseles.

\section{LOS MAYORDOMOS DE LOS PARTIDOS Y LA ORDENANZA DE 1643}

En el siglo XVII la Casa de Velasco contaba con 18 mayordomías, de las que hemos identificado las de Arnedo, Belorado, Berlanga de Duero, Burgos, Briviesca, Frías, Haro, Herrera de Pisuerga, Medina de Pomar, Osma, Pedraza de la Sierra, Salas de los Infantes, Valles de Soba y Ruesga, Villadiego y Villalpando.

En 23 de febrero de 1643 D. Bernardino Fernández de Velasco y Tovar, VII Condestable de Castilla y León y VI duque de Frías, renovaba la ordenanza de mayordomos que había hecho su madre la duquesa Dña. Juana de Córdoba y Aragón 
el 31 de diciembre de $1621^{32}$, de la que no hemos localizado ningún ejemplar. Con leves modificaciones esta misma ordenanza fue reeditada por los Condestables D. Ínigo Melchor Fernández de Velasco y Tovar (1-V-1652) y D. Bernardino Enrique Fernández de Velasco y Tovar ${ }^{33}$, por lo que estamos ante un mismo corpus normativo extendido a todo el siglo XVII. La Casa de Osuna dictó en 1605 otras de similar naturaleza ${ }^{34}$.

La ordenanza de 1643 se componía de 23 artículos. Se ordenaba que cada año los mayordomos liquidaren los alcances que resultaren contra ellos; sólo estarían libres de hacerlo de aquellas deudas y aquellos frutos que con recaudos de los corregidores estuvieren justificadas (art. 1).

Para la recaudación de alcabalas se prefería el encabezamiento con los concejos. Se exigía a los mayordomos que un año antes a la finalización del encabezamiento vigente, el mayordomo, con intervención del corregidor, se informase sobre si podía mantenerse, aumentarlo o disminuirlo enviándolo todo a la Contaduría para que tomase la decisión correspondiente (art. 2). Del nuevo encabezamiento se enviaría copia a la Contaduría (art. 3). Además, no se permitía que los mayordomos se eximiesen del pago de alcabalas, salvo de las cosas de su labrança e criança (art. 4). Si algún pueblo no se encabezare, los mayordomos debían dar cuenta a la Contaduría de quiénes pretenden arrendarlas y las pujas que hacen y, mientras respondía, nombrar por su cuenta y riesgo fieles que las administrasen percibiendo el treinta al millar de lo que cobraren, como en las alcabalas del rey (art. 6). Sobre el modo de ponerlas en administración se dictó otra instrucción de otros 23 artículos $^{35}$. Se describe el mismo procedimiento que seguían la Real Hacienda y los propios concejos cuando el $10 \%$ de los tratos y contratos, que recaudaba un fiel nombrado al efecto, no alcanzaba a cubrir el encabezamiento repartiéndose esa cuantía entre los vecinos de acuerdo al valor de sus haciendas, previamente registradas.

Los arrendamientos de diezmos y otras rentas se deberían hacer previo pregón con intervención de los corregidores cuatro meses antes de que venciera el anterior para que en ese tiempo dispusiese la Contaduría; se prohíbe recibir posturas con prometido, si no fueren claramente al alza, y en todo caso sin que sobrepase el 2 $\%$ quedando el quinto para la hacienda señorial, como en las rentas reales (art. 7). Hecho el arrendamiento se enviaría copia a la Contaduría (art. 8); también, de las tazmías y los repartos de los diezmos de granos (art. 9).

Los mayordomos debían vigilar la buena conservación de los granos en las paneras avisando a la Contaduría si se fuere picando (art. 12). Las ventas del pan deberían ir precedidas de la notificación a la Contaduría de los precios de cada mercado buscando el mejor momento y esperar la orden de venta; los granos de-

32. SN, AHN, Frias, leg. 633/4.

33. SN, AHN, Frías, legs. $1.395 / 48$ y $641 / 188$.

34. "Reglas para la mejor administración y cobro de rentas de los Estados" reformadas en 1695 con la promulgación de unas "reglas para la mejor administración”. I. Atienza Hernández. Aristocracia, poder y riqueza..., pp. 319 y 324.

35. 1643, febrero, 25. Madrid. SN, AHN., Frías, leg. 633/4, ff. 8v-10. 
bían pregonarse públicamente y tomar testimonio de escribano de los precios en que vendían otros (art. 10). De todo se enviaría copia a la Contaduría (art. 11).

Se prohíbe que los mayordomos se dediquen al comercio de granos y al arrendamiento o administración de rentas reales y eclesiásticas por sí o como fiadores de otros (art. 5).

Las rentas de poca importancia, como penas de Cámara y mostrencos, debían cargarse también en la cuenta anual de cada mayordomía (art. 13). Deberían tener libro de penas de Cámara y gastos de justicia pidiendo cuenta de ellas a los receptores y llevando las anotaciones mensualmente; deberían presentarse al dar la cuenta anual (art. 14).

En lo que se refiere al gasto de la mayordomía, se ordena que se reduzcan al máximo las costas en el cobro (art. 15) y que no se tome cantidad alguna por ocupaciones en asuntos de las mayordomías sin el testimonio preciso con intervención de los corregidores y permiso de la Contaduría (art. 16). También se prohibía reparar fortalezas, casas y otros bienes sin seguir el mismo proceso (art. 17). De los repartimientos de subsidio y excusado se exige testimonio de escribano (art. 18), al igual que de los gastos de transporte de pan y del envío de dinero a la Contaduría (art. 19). También estaban obligados a pagar puntualmente los intereses de censos y las otras cargas para evitar ejecuciones contra la hacienda señorial (art. 22). La preocupación por el pago de los censos había llevado al Condestable en 1642 a dictar normas complementarias admitiendo el pago de los intereses en plata, aunque tuviera el derecho a pagarlos en vellón ${ }^{36}$, y a exigir a los mayordomos que enviasen a la Contaduría los traslados de todas las transacciones que hicieren los titulares de los censos con ellos, pues eso hacía que mientras estudiaban el derecho de los nuevos titulares retrasaran el pago de los intereses y acabaran cayendo en ejecuciones judiciales ${ }^{37}$.

36. 1642, junio, 29. Ontiñena. Carta del Condestable en que añadió a la ordenanza de mayordomos de 1621 cuatro capítulos. "Y en quanto a pagar los réditos destos censos en plata, ha de seruirse V. S. de ordenar que se siga la costumbre que hasta aquí ha auido en esta parte, aunque se conozca mi derecho y acción sean llanos para no pagar sino en vellón, porque la calificación desta justicia ha de depender de examinarse los recaudos que se truxeren, y se ha de acomodar o bien por el consentimiento de los acreedores conociendo la razón o siguiéndose en justicia vniformemente para con todos de que ay muchos exemplares y lo contrario no seruirá sino de turbar la paga de los censos, que es materia en que aún no se ha de pensar y de que los mayordomos tengan escusa para no darlas puntuales y que se vayan creciendo réditos que después no pueden satisfacerse". SN, AHN, Frías, leg. 633/4, ff. 7-8.

37. [1642]. "Desde que por muerte de mi madre, que está en el cielo, entré a gouernar mi Estado y hazienda he deseado sumamente que se califique el acción que las personas a quien pago censos tienen para percibir sus réditos, juzgando que acciones y derechos semejantes pasan cada día de vnas personas a otras y que si esta parte por la de los censualistas se errase y con la costumbre y buena fee de ir pagando sin otra atención podría resultar a mi hazienda inconueniente grande y repetirse contra mí lo mal pagado y así he deseado con todas veras calificar estas acciones tomando tanto de las escrituras de censo, cesiones que dellas se ayan hecho, traspasos y embargos y auiéndose dado sobre este particular las órdenes que V. S. sabe veo que por ningún caso se acaua materia que de suyo es tan fácil y que la tengo por de tanta consideración; y, porque algunos mayordomos de mi Estado vsan mal desta orden han intentado dilatar la paga de los censos en sumo deseruicio mío y con riesgo de hazer vn pleito de acreedores sin que ninguna orden de las que sobre este particular se han dado no sólo expresa, pero aún tácitamente obligue a cosa semejante, me ha parecido suplicar a V. S. dé orden apretada para que 
Los mayordomos no debían ir a Madrid a dar cuentas hasta que los llamasen los contadores para que no prolongasen su estancia muchos días y se incrementasen sus dietas (art. 20). Los alcances que resultaren a favor de la hacienda señorial debían entregarlos al tesorero (art. 22).

El papel de los corregidores era esencial para controlar la actuación de los mayordomos; por eso debía enviárseles una copia de esta ordenanza (art. 23).

En la versión de esta ordenanza hecha por D. Bernardino Enrique Fernández de Velasco, X Condestable, se eximía al tesorero de cualquier responsabilidad en lo que respecta al dinero y letras que enviaren los mayordomos, únicos responsables (art. 25), y se exigía a los mayordomos salientes o sus hijos y herederos que entregasen un inventario de los papeles al nuevo mayordomo del que se debía enviar copia a la Contaduría (art. 26).

\section{LAS CAUSAS Y LOS CASOS O EL CONTROL DE LOS MAYORDOMOS}

Para la Casa de Velasco, como para la del Infantado ${ }^{38}$, la selección de mayordomos fue un problema fundamental, que durante el siglo XVII adquirió mayor gravedad. Aunque eran los oficiales más importantes en cada partido, su selección chocaba en muchas ocasiones con la falta de candidatos. En varios partidos no había más que una familia o un grupo de parientes que pudieran asumir la tarea, pues también se requería solvencia para prestar fianza y conexiones económicas para girar las letras a la tesorería en Madrid.

Un buen ejemplo de este problema lo hemos documentado en Osma. En 1 de octubre de 1645 el Condestable escribía a su hermano el marqués del Fresno, a la sazón gobernador de sus estados, ordenándole que cesase a D. Francisco de Cogollos en la mayordomía -y como gobernador- del partido de Osma porque no la servía a su satisfaçión -estaba muy falto de salud y no podía acudir a todo- y que pusiese en ella persona a propósito, avnque se crezca algo el salario ${ }^{39}$.

El marqués del Fresno envió a D. Pedro Olarte de Ago y a D. Juan de Salaçar a Osma a ofrecer la mayordomía a Luis de Soto diciendo V. S. auía puesto los ojos en él y deseaua haçerle merçed y que lo que por ahora se ofrecía era aquel go-

en esta paga de San Iuan todos los mayordomos de mi Estado tomen tanto auténtico autorizado por dos o tres escriuanos de las dichas escrituras y calificación de las personas a quien se pagaren los censos y en cuya cabeza no estuuieren impuestos y si para esto, como siempre se ha ordenado, fuere necesario suspender la paga se ha de depositar ante todas cosas a riesgo del mayordomo con todas las solemnidades necesarias de derecho y autoridad de juez competente y, hecho esto, se han de pedir los recaudos y no antes, quedando protestado y a riesgo del mayordomo o administrador todo lo que en esta parte se faltare y no al de mi hazienda, pues por esta orden no se prohíbe el pagar (...)". SN, AHN, Frías, leg. 633/4, f. $9 \mathrm{v}$.

38. A. Carrasco Martínez. El poder de la sangre..., p. 391.

39. En 2 de noviembre se decía que D. Francisco de Cogollos "está mui acauado, impedido y enfermo y que ya está ináuil por sus achaques de poder asistir a su oficio"; el día 9 y respecto a ir dar cuentas a la Contaduría, que "la qüenta la remitirá con toda breuedad porque él a muchos días anda muy malo y es imposible hirla a dar". SN, AHN, Frías, leg. 1.803/27. 
bierno y mayordomía de que V. S. le haría merçed con la residençia. Sin embargo, Luis de Soto se resistía porque tenía pendientes muchas cobranças y negoçios de su difunto suegro Francisco de Villarroel y una hija que poner en estado; estaba dispuesto a aceptar la mayordomía, pero no la gobernación. Como su parecer era que podía ser conveniente separar ambos oficios, D. Juan de Salazar marchó a Villadiego a buscar alguien para la gobernación. Mientras D. Juan de Salazar resolvía este problema, lo que no consiguió, el marqués del Fresno aparentó aceptar la oferta de Luis de $\mathrm{Soto}^{40}$.

Simultáneamente el marqués del Fresno encargó a D. Fernando de Río y Malo, corregidor de Berlanga de Duero, la búsqueda de otro candidato. Fue Juan de Escalante, vecino de El Burgo de Osma y cuñado del Ldo. Cogollos, mayordomo cesante, al que convenció para aceptar mayordomía y gobernación asegurándole que conforme sus procederes V. S. y el Condestable le han de mejorar conforme los seruicios que hiciere. El marqués del Fresno también acepta a este candidato ordenando que prepare las fianzas que debía prestar que no sean labradores por ser de incombeniente y pidiéndole que tenga casa en Osma ${ }^{41}$. Entonces surgió una nueva dificultad. El Ayuntamiento de Osma protestaba de que se diesen estos oficios a un vecino de El Burgo de Osma porque

la uilla del Burgo siempre a estado y está opuesta contra esta ciudad ansí en cortas de leña de los montes de esta ciudad como en remitirnos soldados de los que llegan a ella e que los aloxemos costeándonos en quanto pueden y en otras cosas que por no cansar a V. Sa. no lo espeçificamos porque de su deseo es ber esta ciudad destruyda y acauado y que el Condestable mi señor pierda su jurisdicción y siendo el juez de la uilla del Burgo, aunque mejor lo quiera açer, a de ser siempre en nuestro daño.

El marqués del Fresno no veía especial problema en ello, pues no lo había habido con D. Francisco de Cogollos, también vecino de El Burgo, y menos lo habría con Juan de Escalante, el más rico de esta villa, que se había mostrado poco interesado en ser gobernador. Además, su presencia en el Ayuntamiento de Osma como gobernador quedaba moderada porque en lo judicial había por encima de él un juez de apelaciones y en lo político sólo tenía un voto; además, Osma podría mandarle aviso de cómo obra. Reconocía que sólo estaban dispuestos a aceptar la administración vecinos de El Burgo, por su proximidad ${ }^{42}$.

Desde Berlanga de Duero continuaba sus gestiones D. Pedro Olarte del Ago sin conocer aún el resultado de las de D. Juan de Salazar en Villadiego. En Berlanga tanteó a María Çapata que tenía un hijo viviendo en Atienza al que quería

40. 1645, octubre, 13. Berlanga de Duero. Carta de D. Pedro Olarte de Ago dirigida al marqués del Fresno.

41. 1645, octubre, 19. El Burgo de Osma. Carta de D. Fernando de Río y Malo al marqués del Fresno.

42. 1645, octubre, 28. Osma. Carta de la Justicia y regimiento de Osma al marqués del Fresno. 
hacer regresar con alguna ocupación y al que calificaba de buen moço, bien entendido y capaz ${ }^{43}$.

Después de sopesar todas las opciones y de considerar la posición del Ayuntamiento de Osma, la Junta de Contadores aceptó a Juan de Escalante si quiere ser sólo mayordomo, quien ya tenía listas las fianzas para darlas ante el corregidor de Berlanga. Se reconocía que D. Francisco de Cogollos, como gobernador, había hecho grandes agrabios a los vecinos de Osma, por lo que Juan de Escalante no lo sería ${ }^{44}$.

Junto al problema de la selección de candidatos se yuxtapone el de evitar fraudes a la hacienda señorial, problema que en una coyuntura depresiva preocupó especialmente a los Condestables y que les llevó a realizar acciones judiciales contra varios de sus mayordomos, casos que pasamos a analizar y de los que no hemos encontrado ejemplos ni antes ni después. En el siglo XVII los mayordomos de la Casa del Infantado tuvieron problemas para recaudar las cantidades a las que se habían obligado, pero no parece que cayeran en fraudes ${ }^{45}$.

En 4 de enero de 1636 un procurador en nombre del Condestable demandó ante el corregidor de Villalpando a Tirso de Benavente, su mayordomo de rentas en esa villa, porque:

- En junio había vendido 160 cargas de trigo de las rentas a 40 y 42 rs. cada carga, parte de ello a las mismas personas que le habían afianzado en la mayordomía, pese a que el Condestable le había ordenado que no lo hiciese; entonces valía en Villalpando y en Balderas a 60 y 70 rs.

- Estando reparando el castillo de Villalpando y teniendo orden de rematar la obra con intervención de su alcaide, lo hizo sin contar con él en 40.000 mrs. más de lo necesario repartiéndolos con los propios postores y permitiéndoles tasar los materiales como quisiesen suponiéndose un incremento en esta partida del cien por cien; admitió la colocación de 500 hojas de lata en el chapitel y, después de contarlas colocadas, sólo eran 340.

- En el reparo de unas casas en Villardiga se había empleado madera y otros materiales procedentes de una casa vieja que por "ab intestato" de Bartolomé Castán perteneció al Condestable y, sin embargo, había cargado 51.556 mrs. como si los hubiera comprado. Para dar validez al fraude y dado que el alcaide de Villalpando no quiso firmar hizo anotar que no lo hacía por estar imposibilitado, lo que era falso.

- Se apropió de la mitad de los diezmos del vino de Villanueva del Campo de los dos años anteriores (más de 300 cántaras) y vendió parte de la otra mitad a sus fiadores a bajo precio.

43. 1645, noviembre, 2. Berlanga de Duero. Carta de D. Pedro de Olarte al marqués del Fresno.

44. 1645, noviembre, 9. El Burgo de Osma. Carta de D. Francisco del Río y Malo al marqués del Fresno.

45. A. Carrasco Martínez. El poder de la sangre..., pp. 402-405. 
Cuadro 1. Valor de los diezmos del vino de Villanueva del Campo

\begin{tabular}{|c|c|c|c|c|}
\hline AÑO & COSECHA (@) & GESTIÓN & ARRENDADORES & VALOR (MRS.) \\
\hline 1630 & 38.970 & administración & & 167.628 \\
\hline 1631 & 78.559 & administración & & 172.584 \\
\hline 1632 & 22.294 & arrendamiento & Antonio Gangoso & 157.000 \\
\hline 1634 & 38.059 & arrendamiento & sus fiadores & 86.000 \\
\hline
\end{tabular}

- No había concertado las alcabalas de los tratos de los sacerdotes, el grupo social de mayor riqueza, defraudando a la hacienda señorial, pero reforzando sus relaciones con ellos. Sus fiadores habían sido el Ldo. Juan Gómez y Bartolomé Hernández, clérigos de Villanueva.

Por todo el Condestable pedía que se le condenase en 286.500 mrs., de los que 55.000 correspondían al fraude en la venta de grano, 75.000 a los reparos de la fortaleza de Villalpando, 16.500 al reparo de la casa de Villardiga, 80.000 a la ocultación de los diezmos de Villanueva del Campo y 60.000 a las alcabalas de los clérigos. El corregidor le condenó a pagar la diferencia hasta 66 rs. por carga por la venta de 90 cargas de trigo de las 170 por las que se le demandaba y 860 rs. por el exceso que había cargado en los reparos de la fortaleza de Villalpando absolviéndole de lo demás ${ }^{46}$. El pleito siguió en apelación ante la Chancillería de Valladolid.

Le sucedió Diego Noblino como mayordomo de Villalpando. En 1651 el Condestable comisionaba a D. Juan de Salazar Velasco ${ }^{47}$ para que le ejecutase, puede suponerse que por no haber liquidado los alcances contra él (debía 400 ducados de un alcance anterior); además, le pide que investigue si ha cometido algún fraude y le pida cuenta de si ha pagado los intereses de censos y otros situados contra su mayordomía. El Condestable también estaba descontento porque había hecho caer el arrendamiento de la dehesa de Villalpando. Por supuesto, le manda que busque otro mayordomo. Son de sumo interés las acusaciones que se vierten contra el hasta entonces corregidor de Villalpando:

Creo que quando lleguéis a Villalpando hallaréis tomando residençia al licençiado Lorenzo Casado, corregidor que ha sido de esta villa, y aunque le halléis con vara es mi voluntad no tratéis nada con él ni le comuniquéis estas órdenes sino sólo a su suçesor porque de todos estos daños ha tenido él la culpa y no es bien que por disculpallos es desayude, mayormente estando oy escluido de mi seruiçio por lo mal que ha cumplido con él.

Cambiemos al partido de Villadiego. En 1649 el Condestable nombró mayordomo a D. Juan de Villegas ${ }^{48}$. En 1653 D. Juan de Huidobro y Velasco, procurador

46. 1636, agosto, 1. Villalpando. SN, AHN, Frias, leg. 1.811/6.

47. 1651, enero, 8. Madrid. SN, AHN, Frías, leg. 1.472/1.

48. SN, AHN, Frías, leg. 512/2. 
general de Villadiego, envió un memorial al Condestable acusándole de cometer fraudes contra la hacienda señorial y contra la república, pues siendo su cosecha muy corta traía granos de fuera que vendía sin pagar los tributos correspondientes; el Condestable dio comisión a D. Baltasar de Cosío Velarde, alcalde mayor de Salas de los Infantes, para que tomase información. En 30 de agosto de 1653 el juez de comisión remitió la causa al Condestable, permaneciendo suspendida hasta abril de 1658, periodo en el que murió el Condestable y en que D. Juan de Villegas se ordenó de presbítero. En 24 de abril de 1658 el Condestable ordenó a D. Francisco de Sandoval Quijano, alcalde mayor de Villadiego, que reanudase el pleito y dio comisión a D. Francisco de Valdivielso Morquecho, entonces mayordomo, para que pidiese a D. Juan de Villegas la restitución de lo defraudado que estimaba en 1.346.284 mrs. D. Juan de Villegas basó su defensa en su fuero eclesiástico pidiendo que se remitiese la causa a los provisores del Arzobispado de Burgos, lo que no fue admitido. Por tratarse también de fraude contra la república el procurador general de Villadiego pidió que se llevase el pleito ante el fiscal real, lo que se ejecutó por auto de 17 de octubre de 1658 y en 12 de marzo de 1659 por otro auto se mandó llevar a la sala de la Chancillería de Valladolid en definitiva.

Se le acusaba de que:

- En 1649 D. Juan de Villegas y el alcalde mayor arrendaron las tercias de los diezmos menudos de Villadiego al Ldo. Tadeo de Ceballos, clérigo y su ýntimo amigo, en menos de la mitad de su valor repartiéndose después los frutos. En 1654 repitió la operación sumando el fraude de ambos años más de $75.000 \mathrm{mrs}$.

- En 1649 este mayordomo resultó alcanzado en 410 fanegas de trigo, que el Condestable le mandó vender en 13 de mayo de 1650 con intervención del alcalde mayor a los mayores precios. Aunque en esta fecha se tasó en 15 rs. cada fanega, el 30 de mayo, en que se vendió a este precio a Rafael Marcos, un panadero pobre y vecino de Sasamón, en el mercado de Villadiego valía ya a 18 rs. por lo que el alcalde mayor se opuso pidiendo que se diese a 16 rs.; realmente el mayordomo se quedó el grano para sí y después lo vendió a más de 30 rs. en Burgos. Se estimaba un fraude de $61.200 \mathrm{mrs}$. El procurador general de Villadiego le acusaba de que para quedarse con este trigo

hizo vna benta finjida a un panadero pobre llamado fulano Corral, vezino de Sasamón, aziéndole escriuir al Condestable quexas del mayordomo de que teniendo conprado el trigo no se le entregaua y, creyendo ser verdad, por el crédito del mayordomo y la panera mandó se entregase a los 15 rs., siendo todo supuesto por dispusizión y traça del mayordomo por no aber pasado grano de trigo a poder del puesto conprador y, lo que peor fue, que no sólo ganó en el engaño los 3 rs. que ban de 15 a 18 en cada fanega, sino que lo guardó para el año siguiente de 651 que fue muy estéril [a] causa de la langosta y lo ynbió a Burgos y otras partes donde lo bendió a 36 rs. fanega ganando en cada una 21 rs.

- El Condestable por carta de 19 de abril de 1650 mandó al mayordomo que enviase a la casa del Condestable en Madrid todo el trigo que tenía, 
que eran 921 fanegas, lo que debía entregar a vnos serranos que con sus carretas yban por ello. En la cuenta de 1650 incluyó 280 fanegas de trigo entregadas a los serranos y se quedó con 180 que dijo no auer podido cobrar de los deudores del Estado a causa de la esterelidad de la cosecha por el daño de la langosta; parte de las carretas marcharon de vacío y con ellas una información falsa en que despusieron unos estudiantes mudando el áuito y los nonbres para que la Contaduría admitiese un precio de 56 rs. por fanega cuando en Madrid valía a 32 suponiendo un fraude de 24 rs. por fanega. Esto producía un daño de 4.320 rs. o 146.880 mrs. para la hacienda señorial.

- En 1650 se le cargaron 436 fanegas de cebada de las 500 de las rentas de este año que vendió a 9 rs. de plata o 13'5 de vellón, operación en la que cometió un fraude de 1.764 rs. o $59.976 \mathrm{mrs}$.

- La alcabala del vino de 1650 se tuvo en administración por falta de arrendador. En este año D. Juan de Villegas, que arrendó esta alcabala a Diego de Mérida, hombre pobre, afianzó a Domingo de Garnica, obligado del abasto del vino tinto y blanco y persona interpuesta que actuaba para el propio mayordomo que así introducía mucho vino que no registraba y no pagaba alcabala; en los demás años repitió esta práctica. Se le acusaba de un fraude en los años 1649-1652 y 1654 de $762.140 \mathrm{mrs}$.

El procurador general de Villadiego le había acusado de que

siendo la alcauala del uino la mayor renta de todas (...) auia de baler más de 800 ducados y por thener trato de meter vino D. Juan de Uillegas contra las ordenanzas $y$ en perjuicio de la alcauala metiéndolo de noche sin rejistro no ay persona que ponga esta renta y el año de 650 fue obligado del uino poniéndolo en caueza de vn vezino y por allársele algunas cantidades de vino metidas de fuera se le hicieron causas dando las cartas de pago a los vezinos de lo que pagan de alcauala con cautela no diziendo la cantidad fija sino que reziuió lo que montó.

Cuadro 2. Rendimiento y fraude en la alcabala del vino de Villadiego

\begin{tabular}{|c|c|c|c|}
\hline AÑO & VALOR SUPUESTO & VALOR CARGADO & FRAUDE \\
\hline 1649 & 305.000 & 169.391 & 136.629 \\
\hline 1650 & 305.000 & 105.546 & 200.408 \\
\hline 1651 & 305.000 & 159.800 & 146.222 \\
\hline 1652 & 305.000 & 230.376 & 75.187 \\
\hline 1653 & 305.020 & 305.020 & \\
\hline 1654 & 305.000 & 202.835 & 103.187 \\
\hline
\end{tabular}


- En 2 de julio de 1652 D. Juan de Villegas compareció ante el corregidor de Villadiego porque había recibido noticia de la baja de la moneda de vellón por lo que debía resellarse diciendo que tenía 1.200 rs. de las rentas del Condestable y por carta de 14 de agosto el Condestable le mandó remitir 1.200 rs. a Burgos, lo que efectivamente ejecutó. Sin embargo, el procurador general de Villadiego le acusaba de que al publicarse la baja de la moneda de vellón no tenía ningún dinero y que no sólo lo había pedido prestado -a Domingo de Garnica- para hacer el registro sino que también había duplicado el peso de los talegos -había pesado un talego dos veces-. Por eso, el Condestable le pedía 5.350 rs.

Conocemos otro caso similar, que hemos analizado en otra parte, protagonizado por D. Antonio de Santa Gadea, mayordomo del partido de Salas de los Infantes $(1678-1688)^{49}$. El primer problema surgió en 1682, cuando empezó a sospecharse que no hacía todo lo que estaba en sus manos para renovar el encabezamiento de alcabalas de los pueblos de su partido, lo que hizo que en 1683 Barbadillo de Herreros con intervención del superintendente de Rentas Reales y Millones de Burgos consiguiera una rebaja del $20 \%$ y otros pueblos se negaran a encabezarse sin una rebaja similar. Además, de 1684 a 1686 no acudió a dar las cuentas a la contaduría, por lo que finalmente fue ejecutado. Para el Condestable, D. Antonio de Santa Gadea, cargado de problemas económicos, defendía sus propios intereses y no los de su mayordomía por lo que contemporizaba con las distintas villas y lugares, no las apremiaba en los pagos ni usaba sus influencias para obligarlas a firmar los encabezamientos de alcabalas en los términos deseados.

En 1703 se produjo otro desencuentro con un mayordomo, pero porque no pagaba el alcance de su mayordomía ${ }^{50}$. D. Juan Bautista de Beaumont, mayordomo de rentas y teniente de gobernador de Arnedo, llegado el mes de abril de 1704 no había comparecido en la contaduría a dar cuentas. Inmediatamente fue nombrado nuevo mayordomo D. Sancho Manuel Ximénez de Antillón y se le dio poder juntamente con D. Justo de Argaiz, caballero de la Orden de Santiago, ambos vecinos de San Asensio, para que compareciesen ante el gobernador u otras justicias solicitando que se nombrasen contadores que formasen las cuentas. D. Juan Bautista de Beaumont trató de defenderse diciendo de forma poco convincente que

los efectos que tocan a Su E. el Condestable de Castilla, mi señor, en esta dicha ciudad y su jurisdicción y villas eximidas en este presente año no a perciuido cosa alguna ni pedídola a las personas que están a su cargo porque no auía motiuo ni razón para ello por no estar cumplidos los tercios y plazos y no están los tiempos para cobrar adelantado, que para cobrar adelantado asta fin de 1703 a despachado a Joseph Alonso a las villas de Vergara y El Villar y, aunque a echo diferentes dilixencias para su consecuzión y no lo a podido conseguir a causa de estar los vezinos muy pobres asta cojer sus frutos.

49. J.A. Cuesta Nieto. Sociedad y economía en la comarca de la Demanda en la Edad Moderna. Tesis doctoral. Universidad de Castilla-La Mancha. Ciudad Real, 2007, pp. 1.144-1.146.

50. SN, AHN, Frias, leg. 282/25-59. 
Se nombraron contadores por ambas partes y se formaron las cuentas de 1703 cerrándolas en 15 de julio de 1704. En 22 de octubre la justicia de Arnedo pronunció auto aprobándolas y mandando remitirlas a la contaduría del Condestable. D. Juan Bautista de Beaumont resultó alcanzado en 9.871 rs. 8 mrs. por la suma de cuatro partidas de gasto que no le fueron aceptadas:

- 239 rs. del coste de una cargas de peras (14@) que envió al Condestable en el mes de agosto y que éste consideraba que sólo podían tenerse por presente y regalo. Además, no constaba que se recibieran.

- $\quad 1.125$ rs. de los gastos que tuvo con los ministros del corregidor de Logroño cuando fueron a Arnedo a cobrar unas medias annatas, que no se pagaron. Se había hecho sin orden expresa del Condestable.

- 866 rs. de reparos urgentes hechos en el palacio del Condestable en 1699 y que no se habían pasado en las cuentas de 1700 ni en las posteriores. Era precisa licencia del Condestable para reparos que excedieran de $3.000 \mathrm{mrs}$.

- 2.000 rs. que el mayordomo decía haber enviado a D. Sebastián Castellón, secretario del Condestable ya fallecido, para comprar unas mulas. Debió enviar el dinero al tesorero; no quedaba recibo de ello.

A estos 9.871 rs. $11 \mathrm{mrs}$. de alcance de 1703 había que sumar otros 60.258 rs. $11 \mathrm{mrs}$. de alcances de las cuentas cerradas hasta fin de 1702; en total, estaba alcanzado en 70.129 rs. 19 mrs. De esta deuda, entregó o se le ejecutaron en bienes 52.935 rs. 2 mrs. hasta marzo de 1706, incluidos 2.200 rs. que le perdonó el Condestable, por lo que aún debía 17.194'5 rs. En 26 de marzo de 1706 D. Juan Bautista de Beaumont y su hijo D. Joseph intentaron que se levantara el embargo de sus bienes alistándose en la Guerra de Sucesión; la nobleza había sido convocada para luchar contra Aragón y Valencia y ellos pretendían acudir a la guerra conforme a su calidad, lo que a sus ojos justificaba el desembargo de sus bienes para tan noble fin.

Este tipo de actuaciones por parte de mayordomos de rentas y corregidores señoriales debió ser bastante común en el siglo XVII, como muestran los casos citados por I. Atienza Hernández en el ducado de Osuna donde también se produjo una reacción señorial en el tercer cuarto del siglo para cortar estos abusos ${ }^{51}$. El duque de Medina Sidonia mostraba la misma desconfianza hacia sus criados a mediados del siglo XVII ${ }^{52}$. En frase de E. Soria Mesa, se estaba produciendo una paulatina transferencia de poderes de los señores a estos oligarcas, hasta entonces meros poderes intermedios ${ }^{53}$. La actuación de los Condestables sirvió no sólo para mantener el máximo rendimiento de sus rentas, sino también para controlar el desarrollo de las oligarquías de gran parte de sus estados, base de la contestación antiseñorial.

51. I. Atienza Hernández. Aristocracia, poder y riqueza..., pp. 321-322.

52. L. Salas Almela. Medina Sidonia..., pp. 420-421.

53. E. Soria Mesa. Señores y oligarcas: los señoríos del Reino de Granada en la Edad Moderna. Granada, 1997, pp. 211-237. 


\section{CONCLUSIÓN}

La situación financiera de la aristocracia castellana, no precisamente boyante ya en la segunda mitad del siglo $\mathrm{XVI}^{54}$, se vio gravemente afectada por la enorme presión tributaria que la política del Conde-duque de Olivares ejerció sobre Castilla, la cual, al decir de A. Domínguez Ortiz, descansó en gran parte sobre las arcas de la nobleza, tanto por la exigencia de que levantaran tropas a su costa (a partir de 1632), la obligación de acudir a la guerra personalmente, la petición de donativos, el descuento de la mitad de los juros o porcentajes mayores, la reivindicación de las alcabalas por la Real Hacienda las cuáles sólo se cedían después de pagar grandes sumas y otros expedientes ${ }^{55}$. Estos aspectos han sido reconsiderados por B. Yun Casalilla que ha tratado de cuantificar y periodizar el endeudamiento de la nobleza castellana y valorar este proceso dentro del modelo de gestión de las economías nobiliarias; según explica, este endeudamiento se intensificó a partir de 1580, pero los servicios a la monarquía entre 1580 y 1640 representarían sólo el 42’6\% del endeudamiento, mientras las mercedes recibidas de la propia monarquía por sus servicios sobrepasaron ampliamente el importe total de ese endeudamiento que estaba puesto al servicio de la promoción pública de las casas nobiliarias ${ }^{56}$. Sin embargo, esta economía señorial sufrió un periodo de dificultades a partir de 1630 por la contracción de la renta señorial y por la reducción de la concesión de mercedes que caracterizó la política del conde-duque de Olivares; como respuesta los nobles trataron de mejorar la gestión de sus patrimonios fomentando la población de sus estados y favoreciendo a sus vasallos cuando sus rentas procedían de tercias

54. M. Diago Hernando. "El endeudamiento de la alta nobleza castellana durante la primera mitad del siglo XVI: El caso del segundo conde de Monteagudo (1506-1547)", Chronica Nova, 39 (2013), pp. 175-203. M.A. Moreno Ramírez de Arellano. "La quiebra de la casa de Arellano en el contexto de la crisis castellana de finales del siglo XVI: Análisis de las causas determinantes del concurso de acreedores recaído sobre el Señorío de Cameros y Condado de Aguilar en 1592", Berceo, $\mathrm{n}^{\circ}$ 114-115 (1988), pp. 155-170. Ch. Jago. "La «crisis de la aristocracia» en la Castilla del siglo XVII", en J.H. Elliot (ed.). Poder y sociedad en la España de los Austrias. Barcelona, 1982, pp. 247-286. A. Domínguez Ortiz. Las clases privilegiadas en el Antiguo Régimen. Madrid, 2012, pp. 100-105.

55. A. Domínguez Ortiz. Las clases privilegiadas en el Antiguo Régimen. Madrid, 2012, pp. 98-100, y La sociedad española en el siglo XVII..., pp. 228-233. Sobre las razones por las que su padre D. Juan Fernández de Velasco, VI Condestable, dejó esta situación financiera ver B. Yun Casalilla. La gestión del poder. Corona y economías aristocráticas en Castilla (siglos XVI-XVIII). Madrid, 2002, pp. 29-31.

56. El $42^{\prime} 6 \%$ de los censos se impuestos por 27 casas señoriales entre 1580 y 1640 fue para servir a la monarquía (18’4 \% para servicios militares, 16’1\% para gastos de representación en actos cortesanos y $7 \%$ para servicios diplomáticos y cargos públicos) mientras el otro $58 \% 4 \%$ lo emplearon en la propia política familiar (7\% en mejoras de los mayorazgos, $38^{\prime} 9 \%$ en dotes y $12{ }^{\prime} 4 \%$ en deudas con banqueros o absorción de otras cargas). Para valorar la relación entre endeudamiento y mercedes, considera el caso del conde de Benavente, que entre 1580 y 1624 se cargó con principales de censos y réditos por importe de 400.630 ducados y que por distintas mercedes recibió de la Corona la importante suma de 738.368 ducados; hay que incluir entre esas mercedes la reducción en 1607 del tipo de interés del 7’14 \% al 5 \%. B. Yun Casalilla. La gestión del poder..., pp. 167-182. 
y alcabalas o si no aumentando la presión sobre sus vasallos (monopolios...) y sus recursos (montes y pastos) ${ }^{57}$.

La Casa de Velasco sufrió durante el siglo XVII estas mismas situaciones. Bernardino Fernández de Velasco y Tovar, VII Condestable, heredó la Casa en 1613; entonces tenía más de 400.000 ducados tomados a censo y había perdido los diezmos del mar que rentaban 200.000 ducados al año; sus rentas, incluida la encomienda, habían pasado de 78.000 ducados a 34.000 en 1631 cuando los intereses de los censos que pagaba sumaban 30.000 ducados $(1643)^{58}$.

Los Condestables fueron conscientes de estas tensiones internas y desarrollaron todo un programa tendente a eliminarlas. Así, la Casa de Velasco fue una de las grandes casas señoriales que no acabó devorada por los intereses de los censos y siendo concursada y sus rentas intervenidas por un juez ${ }^{59}$; de los 30.000 ducados de intereses de censos que pagaba en 1643 pasó a pagar 20.000 en 1683 , es decir, un $33{ }^{\prime} 3 \%$ menos $^{60}$. Hemos tratado de añadir otro enfoque. Como respuesta a este desequilibrio financiero, los duques de Frías se preocuparon por racionalizar la administración de sus estados e intensificar el control sobre sus oficiales sometiendo a los mayordomos de los partidos, insertados en sus oligarquías, a una estrecha vigilancia ${ }^{61}$, generando una dinámica que pudo ser similar a la descrita para el ducado de Feria en el siglo XVIII ${ }^{62}$. Para ello fue importante mantener separados los oficios de administración de los de justicia; los corregidores y alcaldes mayores de las villas cabeza de partido y sus merinos, dependientes directamente de los Condestables, fueron los encargados de ejecutar las órdenes contra los mayordomos, parientes y allegados de los alcaldes ordinarios y de los clérigos de esas mismas villas, razón por la cual se evitó acumular los corregimientos con las mayordomías, aunque fuera difícil pagar sus salarios.

57. B. Yun Casalilla. La gestión del poder..., pp. 188-193.

58. A. Domínguez Ortiz. La sociedad española en el siglo XVII..., pp. 235-236.

59. B. Yun Casalilla. La gestión del poder..., pp. 163-196. Esta situación también se dio en el reino de Valencia donde durante el reinado de Felipe IV entre 50 y 60 de los 157 señores laicos vieron secuestradas sus rentas a manos de la Corona para pagar a sus acreedores. J. Casey. El Reino de Valencia en el siglo XVII. Madrid, 1983, p. 149.

60. A. Domínguez Ortiz. La sociedad española en el siglo XVII..., p. 236.

61. En esta tarea, los jueces de residencia fueron ineficaces, pues su actuación iba dirigida a controlar a las justicias locales y a los oficiales concejiles y no a los mayordomos de rentas señoriales; pese a que detectaron las injusticias cometidas por las oligarquías concejiles en los repartimientos fiscales que producían una reducción de las rentas, fueron incapaces de mejorar la recaudación. A. Carrasco Martínez. Control y responsabilidad en la administración señorial. Los juicios de residencia en las tierras del Infantado (1650-1788). Valladolid, 1991, pp. 62-63.

62. S. Aragón Mateos. El señor ausente. El señorio nobiliario en la España del setecientos: la administración del ducado de Feria en el siglo XVIII. Lleida, 2000. 


\section{BIBLIOGRAFÍA}

Aragón Mateos, Santiago. El señor ausente. El señorío nobiliario en la España del setecientos: la administración del ducado de Feria en el siglo XVIII. Lleida, 2000.

Atienza Hernández, Ignacio. Aristocracia, poder y riqueza en la España moderna. La Casa de Osuna, siglos XV-XIX. Madrid, 1987.

Calderón Ortega, José Manuel. "El gobierno y la administración de un Estado Señorial: El Consejo de los Duques de Alba (1484-1531)", En la España Medieval, no 19 (1996).

- El Ducado de Alba. La evolución histórica, el gobierno y la hacienda de un estado señorial (siglos XIV-XVI). Madrid, 2005.

—. "El gobierno de la Casa de Alba (siglos XIV-XVI)", en Ser Quijano, Gregorio del (coord.). Congreso V centenario del nacimiento del III duque de Alba Fernando Álvarez de Toledo. Ávila, 2008, pp. 119-153.

Carrasco Martínez, Adolfo. El régimen señorial en la Castilla Moderna: Las tierras de la Casa del Infantado en los siglos XVII y XVIII. Tesis doctoral. Madrid, 1991, pp. 90-166,

- Control y responsabilidad en la administración señorial. Los juicios de residencia en las tierras del Infantado (1650-1788). Valladolid, 1991.

—. El poder de la sangre. Los duques del Infantado. Madrid, 2010.

Casey, James. El Reino de Valencia en el siglo XVII. Madrid, 1983.

Cuesta Nieto, José Antonio. Sociedad y economía en la comarca de la Demanda en la Edad Moderna. Tesis doctoral. Ciudad Real, 2007.

Diago Hernando, Máximo. "El endeudamiento de la alta nobleza castellana durante la primera mitad del siglo XVI: El caso del segundo conde de Monteagudo (1506-1547)", Chronica Nova, 39 (2013), pp. 175-203.

Domínguez Ortiz, Antonio. La sociedad española en el siglo XVII. I. El estamento nobiliario. Granada, 1992.

—. Las clases privilegiadas en el Antiguo Régimen. Madrid, 2012.

Franco Silva, Alfonso. Entre los reinados de Enrique IV y Carlos V. Los Condestables del linaje Velasco (1461-1559). Jaén, 2006.

García Hernán, David. Aristocracia y señorío en la España de Felipe II. La Casa de Arcos. Granada, 1999.

- El gobierno señorial en Castilla. La presión y concesión nobiliaria en sus documentos (siglos XVI-XVIII). Madrid, 2010.

González Crespo, Esther. Elevación de un linaje nobiliario castellano en la Baja Edad Media: los Velasco. Tesis doctoral. Madrid, Universidad Complutense, 1981.

Gómez Vozmediano, Miguel Fernando. "La gestión patrimonial de la aristocracia castellana. Burocracia señorial, práctica contable y reflejo documental (siglos XV-XVIII)", en Alloza Aparicio, Ángel, Fernández Izquierdo, Francisco, y García Guerra, Elena (eds.). Comercio, banca y sociedad en los reinos hispánicos (siglos XIV-XVIII), pp. 227-277. 
Guilarte, Alfonso María. El régimen señorial en el siglo XVI. Valladolid, 1988.

Jago, Charles. "La «crisis de la aristocracia» en la Castilla del siglo XVII", en John H. Elliot (ed.). Poder y sociedad en la España de los Austrias. Barcelona, 1982, pp. 247-286.

Moreno Ramírez de Arellano, Miguel Ángel. "La quiebra de la casa de Arellano en el contexto de la crisis castellana de finales del siglo XVI: Análisis de las causas determinantes del concurso de acreedores recaído sobre el Señorío de Cameros y Condado de Aguilar en 1592”, Berceo, nº 114-115 (1988), pp. 155170.

Ortuño Molina, Jorge. Realengo y señorío en el Marquesado de Villena. Organización económica y social en tierras castellanas a finales de la Edad Media (1475-1530). Murcia, 2005.

Salas Almela, Luis. Medina Sidonia. El poder de la aristocracia, 1580-1670. Madrid, 2008.

Soria Mesa, Enrique. Señores y oligarcas: los señoríos del Reino de Granada en la Edad Moderna. Granada, 1997.

Valencia Rodríguez, Juan Manuel. El poder señorial en la Edad Moderna: La casa de Feria (siglos XVI-XVII). 2 tomos. Cáceres, 2010.

Yun Casalilla, Bartolomé. La gestión del poder. Corona y economías aristocráticas en Castilla (siglos XVI-XVIII). Madrid, 2002.

Fecha de recepción del artículo: febrero 2014

Fecha de aceptación y versión final: abril de 2014 
